\title{
VINCULAÇÃO DE RECEITA MÍNIMA PARA A SATISFAÇÃO DO DIREITO À EDUCAÇÃO NO BRASIL (CF, ART. 212) \\ DIRIGISMO CONSTITUCIONAL E DEVER DE PROGRESSIVIDADE
}

\author{
Amanda Costa Thomé Travincas*
}

\begin{abstract}
RESUMO
Este estudo propõe-se a discutir em que termos a vinculação de receita mínima para a satisfação do direito à educação, no âmbito do artigo 212 da Constituição Federal, não converge para um descompromisso estatal em face do dever de progressividade ínsito aos direitos sociais, na medida em que a observância do mínimo, no âmbito dos entes federativos, tem o condão de efetivar a tarefa constitucional, abandonando a premissa do que é acobertado sob o termo de dirigismo constitucional, qual seja a conferência da máxima eficácia e efetividade dos direitos fundamentais. $\mathrm{Na}$ oportunidade, constrói-se uma leitura apta a conciliar a fixação de mínimos constitucionais com o dever de satisfação progressiva do direito à educação, desde o contexto brasileiro.
\end{abstract}

PALAVRAS-CHAVE: Direito à educação; Vinculação de receitas públicas; Dever de progressividade.

* Mestre e Doutoranda em Direito pela PUCRS. Professora universitária em São Luís - MA. 


\title{
MINIMUM REVENUE OF BINDING TO SATISFACTION THE RIGHT TO EDUCATION IN BRAZIL (CF, ART 212.) - CONSTITUTIONAL DIRIGISM AND PROGRESSIVITY DUTY
}

\begin{abstract}
This study aims to discuss on what terms linking minimum revenue for the satisfaction to the right to education, under Article 212 of the Federal Constitution, does not converge to state disengagement in the face of progressivity duty embedded in social rights, as far as compliance with its minimum, under the federal entities, have the power to implement the constitutional task, abandoning the premise of which is covered up under the constitutional dirigism term, which is the guarantee of the maximum efficiency and effectiveness of fundamental rights. On that occasion, it is built a reading apt to reconcile the establishment of constitutional minimum with the duty of progressive realization of the right to education, from the Brazilian context.
\end{abstract}

KEYWORDS: right to education; link to public revenues; duty of progressivity

\section{NOTAS INTRODUTÓRIAS}

A Constituição Federal, em seu artigo 34, VII, prevê, enquanto pressuposto material a ensejar a decretação de intervenção da União nos Estados e no DF, a hipótese de violação dos designados princípios sensíveis, dentre os quais figura a aplicação do mínimo exigido da receita resultante de impostos estaduais, compreendida a proveniente de transferências, na manutenção e desenvolvimento do ensino e nas ações e serviços públicos de saúde (alínea e). 0 dispositivo encontra equivalente no artigo 35, III da CF, reservado a elencar o mesmo pressuposto para a decretação de intervenção estadual nos municípios. Tais enunciados remetem, implicitamente, ao assegurado pelo artigo 212 da CF, na base do qual se assenta a opção constituinte de vincular receitas públicas para a satisfação do direito à educação no Brasil. Temse que o descumprimento do dever decorrente da vinculação de recursos constitui fato que põe em risco a estabilidade da ordem 
constitucional, de sorte a justificar a ocorrência de um estado de legalidade extraordinária que visa à estabilização e proteção da Constituição por meio da adoção de medida de excepcionalidade para a superação da crise gerada. Disto se pode aduzir que a inércia estatal ou a sua atuação aquém do minimum definido na Constituição é, por opção constituinte, elemento caracterizador de instabilidade, posto que fragiliza a própria democracia, desafinando a promoção de um direito social basilar, qual seja o direito à educação.

A importância conferida pela Constituição tocante à proteção e promoção do direito à educação é ainda inconteste se se compreende o aludido artigo 212 como manifesta decisão de redução da esfera deliberativa dos poderes constituídos quanto à determinação parcial do quantum a ser destinado ao referido fim social. A vinculação de receitas é decisão que tem o condão de conferir suporte às ações estatais futuras em determinado diâmetro. No tocante à educação, retira-se da vinculação constitucional, de logo, a obrigação de os entes federados atuarem neste âmbito aplicando recursos em dimensão não inferior aos percentuais firmados no texto constitucional.

Se, num primeiro recorte, o propósito se afina ao dever geral do Estado Federal quanto à realização de políticas públicas em matéria educacional, não se pode afastar, à partida, a inferência de que, uma vez satisfeita a hipótese fática da norma, isto é, tendo os entes federados executado as suas obrigações mínimas, também terão atuado definitivamente e de modo satisfatório na promoção e proteção do direito à educação.

Tendo por certo que tal asserção esbarra no dever de conferir máxima eficácia e efetividade aos direitos sociais, este artigo se volta a construir uma interpretação constitucionalmente adequada do artigo 212 da CF, na conjuntura do dirigismo constitucional brasileiro e do reconhecimento do dever de progressividade costurado aos direitos sociais. 


\section{DIRIGISMO CONSTITUCIONAL, DEVER DE PROGRESSIVIDADE E DIREITOS SOCIAIS: O CASO DO DIREITO À EDUCAÇÃO}

No perímetro da dogmática constitucional, é consensual que a previsão normativa de direitos fundamentais pressupõe a existência de deveres de natureza estatal. É ainda verdade que a teoria dos deveres fundamentais passa a ocupar um lugar de centralidade nessa seara desde a admissão da relação inequívoca entre o estabelecimento de deveres e a eficácia e efetividade dos direitos fundamentais. Dentre os deveres estatais - que são múltiplos, dada a compreensão dos direitos como feixes de posições juridicamente protegidas ${ }^{1}$-, destaca-se aquele que culmina no impedimento de regressão dos graus de satisfação dos direitos fundamentais já alcançados por intermédio de decisões estatais desde a eliminação de prestações sociais sem o fornecimento de alternativas ou compensações ${ }^{2}$. A assim chamada proibição de reversibilidade ${ }^{3}$ destaca-se na condição de verdadeiro escudo no contexto de Estados Constitucionais marcados pela (ainda) precariedade da efetivação de direitos, nada obstante a, já não tão recente, consagração constitucional destes ${ }^{4}$.

A rigor, a projeção da proibição de reversibilidade como trunfo argumentativo contra qualquer sorte de redução da proteção conferida a um direito fundamental vem a reforçar o propósito de garantir segurança jurídica e proteger a confiança

1 Na definição conferida por Robert Alexy à expressão direito fundamental como um todo, em ALEXY, Robert. Teoria dos direitos fundamentais. São Paulo: Malheiros, 2008. p. 249.

2 QUEIROZ, Cristina. O principio da não reversibilidade dos direitos fundamentais sociais. Coimbra: Coimbra, 2006. p. 67.

3 Trata-se de termo que encontra um vasto espectro de sinônimos na doutrina, os quais são usados aqui indistintamente, a dizer: proibição de retrocesso social (Ingo Sarlet), proibição de regressividade (Christian Courtis), proibição da evolução reacionária (Canotilho), entre outros.

4 José de Melo Alexandrino chama de tempo dos direitos este lapso temporal entre a positivação de direitos fundamentais em Cartas Constitucionais e o alcance de um patamar adequado de satisfação. Assim, cf. ALEXANDRINO, José de Melo. Direitos fundamentais. Estoril: Princípia, 2007. p. 28-29. 
que os cidadãos depositam no Estado quanto à manutenção dos ganhos e das expectativas, o qual é depreendido, por exemplo, da instituição de cláusulas pétreas (CF, 60, §4ํㅜ) e do chamado direito adquirido ( $\mathrm{CF}, 5^{\circ}$ o, $\mathrm{XXXVI}$ ) no texto constitucional brasileiro ${ }^{5}$. Ocorre que, no âmbito da dogmática constitucional, o preceito tem merecido tratamento específico no contexto da tese dos limites às restrições aos direitos fundamentais. Essa teoria se ocupa de firmar elementos de controle do poder restritivo estatal, uma vez aceita a restringibilidade geral dos direitos fundamentais como uma consequência de sua estrutura principiológica ${ }^{6}$. Nesse sentir, a proibição de retrocesso serviria como barreira ao agir do Estado, ao lado de outros mecanismos de controle, entre os quais, a proporcionalidade, a proteção do conteúdo essencial dos direitos fundamentais e o mínimo existencial.

Compreendendo-se como restrição qualquer afetação desvantajosa ao âmbito protegido por uma norma de direito fundamental ${ }^{7}$, a proibição de reversibilidade atua como condicionante que visa resguardar todos os direitos e as dimensões que lhes são comuns ${ }^{8}$. É evidente que a problemática se perfaz, em maior

5 Para uma fundamentação ampla da proibição de retrocesso social com especial atenção ao caso brasileiro, cf. SARLET, Ingo Wolfgang. A eficácia dos direitos fundamentais. 12 ed. Porto Alegre: Livraria do Advogado, 2014. p. 464-6.

6 ALEXY, Robert. Teoria dos direitos fundamentais. São Paulo: Malheiros, 2008. p. 124-130 e 584, enfatizando que o legislador democrático possui uma discricionariedade estrutural para sopesar. No Brasil, SILVA, Virgílio Afonso da. Os direitos fundamentais e a lei: a constituição brasileira tem um sistema de reserva legal?. In: BINENBOJM, Gustavo; SARMENTO, Daniel; SOUZA NETO, Cláudio Pereira de. (Orgs.). Vinte anos da constituição federal de 1988. Rio de Janeiro: Lumem, 2009. p. 605-618.

7 A definição é de NOVAIS, Jorge Reis. As restrições aos direitos fundamentais não expressamente autorizadas pela constituição. Coimbra: Coimbra, 2003. p. 192 et seq.

8 No mesmo sentido, SARLET, Ingo Wolfgang. Posibilidades y desafíos de un derecho constitucional común latinoamericano. Un planteamiento a la luz del ejemplo de la llamada prohibición de retroceso social. Revista de derecho constitucional europeo. n. 11, 2009. p. 100. No âmbito do Supremo Tribunal Federal, a aplicação da categoria à dimensão negativa já mereceu acolhi- 
medida, no debate acerca da afetação da dimensão positiva dos direitos fundamentais, quando salta à vista a questão de sua incidência sobre os chamados direitos derivados a prestações, os quais, na conhecida acepção de Canotilho, configuram autênticos direitos subjetivos negativos ${ }^{9}$.

Com efeito, a proibição de reversibilidade dos direitos fundamentais é dotada, simultaneamente, de uma faceta negativa, que impõe abstenções ao Estado, impedindo-o de afetar as parcelas satisfeitas de um direito fundamental, e uma face positiva, a qual evidencia a necessidade de proteção eficiente do quantum conquistado, além de obstar a paralisia estatal, determinando a promoção progressiva de direitos, tal qual acentuado em documentos internacionais de direitos humanos e reforçado por teorias como a do constitucionalismo dirigente.

Nesse seguimento, é de destacar o artigo 2.1 do Pacto Internacional de Direitos Sociais, Econômicos e Culturais, doravante PIDESC, o qual determina, in verbis, que "cada um dos Estados -partes [...] compromete-se a agir, quer com o seu próprio esforço, quer com a assistência e cooperação internacionais, especialmente nos planos econômico e técnico, no máximo dos seus recursos disponíveis, de modo a assegurar progressivamente o pleno exercício dos direitos reconhecidos no [...] Pacto por todos os meios apropriados, incluindo articulação por meio de medidas legislativas". De seu turno, o direito à educação recebe acolhimento expresso no artigo 13, §1ํㅡㄹ, segundo o qual "os Estados-partes [...] reconhecem o direito de toda pessoa à educação. Concordam em que a educação deverá visar ao pleno desenvolvimento da personalidade humana e do sentido de sua dignidade e a fortalecer o respeito pelos direitos humanos e liberdades fundamentais.

mento. Veja-se, por exemplo, a afirmação de que "o princípio da proibição de retrocesso, (...) seria aplicável também aos direitos políticos, dentre os quais a invulnerabilidade do segredo de voto", cf. BRASIL. STF. ADI 4543 MC/ DF, Rel. Min. Cármen Lúcia. Julgada em: 19.10.2011.

9 CANOTILHO, José Joaquim Gomes. Direito constitucional e teoria da constituição. 7 ed. Coimbra: Almedina: 2003. p. 338-9. 
Concordam ainda que a educação deverá capacitar todas as pessoas a participar efetivamente de uma sociedade livre, favorecer a compreensão, a tolerância e a amizade entre todas as nações e entre todos os grupos raciais, étnicos ou religiosos e promover as atividades das Nações Unidas em prol da manutenção da paz".

Tais dispositivos, que incidem efeitos na conjuntura jurídica brasileira ${ }^{10}$, reclamam um conjunto de definições de ordem interpretativa para a sua aplicação, notadamente, e em primeira linha, no que diz com a determinação do objeto de sua proteção. O deslinde desta constatação foi a criação do Comitê de Direitos Econômicos, Sociais e Culturais, cujo objetivo é "esclarecer o sentido de alguns direitos e suas correspondentes obrigações com os Estados"11 por meio da prática de emissão de Observações Gerais. Relativamente ao direito à educação, se volta a OG no 13/1999 a definir que, a despeito dos obstáculos estruturais e de outra natureza que impedem a aplicação plena do comando geral estatuído no artigo 2.1 do Pacto, a educação é um dos maiores investimentos financeiros que um Estado pode fazer, considerada a sua condição de pressuposto para pleno exercício de outros direitos ${ }^{12}$.

O eixo central do artigo 2.1 do PIDSC - e também o cerne da controvérsia que gera - parece acomodar-se nos deveres estatais de a) agir no máximo dos recursos disponíveis e b) de modo a assegurar progressivamente o pleno exercício dos direitos. Nessa seara encontram-se circunscritos elementos fulcrais da teoria

10 A recepção do PIDESC no Brasil se deu por meio do Decreto no 591, de 6 de julho de 1992. Posta a sua precedência em relação à Emenda Constitucional no 45 e, precisamente, ao parágrafo $3^{\circ}$ do artigo 5ํ da CF por ela incluído, sublinha-se a sua natureza de norma de status supralegal.

11 ABRAMOVICH, Victor; COURTIS, Christian. Direitos sociais são exigíveis. Porto Alegre: Dom Quixote, 2011. p. 86.

12 OBSERVAÇÃO geral no 13 do Pacto Interacional de Direitos Econômicos, Sociais e Culturais = OBSERVACIÓN general no 13 del Pacto Internacional de Derechos Económicos, Sociales y Culturales. Disponível em: <http://www. servindi.org/pdf/ObservacionesyRecomendaciones Generales.pdf >. Acesso em: 10 out. 2014. 
dos direitos fundamentais, como a noção de reserva do possível, de máxima eficácia e efetividade dos direitos e, finalmente, de proibição de retrocesso. É de notar que, neste particular, a proibição de retrocesso depreende-se da ideia de progressividade, que significa o avanço paulatino das condições necessárias para a garantia de um direito ${ }^{13}$. Se este é o caso, pode-se inferir que não só o regredir é vedado pela norma como, inclusive, e expressamente, o mover-se é ordenado. Não por outra razão, asseguram Abramovich e Courtis que há sempre um ônus de justificar a) o retrocesso, b) o não movimento e, ainda mais, c) o não movimento em maior rapidez, pois é preciso dar passos em prazo breve ${ }^{14}$.

No Brasil, admite-se preponderante a tese de que a vedação de reversibilidade tem caráter relativo, podendo o Estado retroagir em cenários de escassez acentuada. No plano diametralmente oposto, poder-se-ia alegar - de algum modo plasticamente - que o Estado tem um dever de cariz absoluto de não regredir, mantendo o grau de satisfação dos direitos e, desejavelmente, progredindo quanto à satisfação deles, independente do contexto ${ }^{15}$. A despeito de qualquer divergência doutrinária quanto ao alcance da vedação, quer sob um viés absoluto, quer sob uma perspectiva relativa, o preceito é sinônimo de limitação do poder decisório estatal, condicionando, em graus diferenciados, a reformulação das estratégias do Estado para o futuro.

Impende advertir que o ônus probatório da impossibilidade de satisfação de um direito na medida pleiteada é sempre do Estado, sendo acertado presumir, a partida, sua capacidade promocional e, ao mesmo passo, a presunção de inconstituciona-

13 COURTIS, Christian. La prohibición de regressividad em matéria de los derechos sociales: apuntes introductorios. In: COURTIS, Christian. Ni um paso atrás: la prohibición de regresividad em matéria de derechos sociales. Buenos Aires: Del Puerto, 2006. p. 3-52, passim.

14 ABRAMOVICH, Victor; COURTIS, Christian. Direitos sociais são exigíveis. Porto Alegre: Dom Quixote, 2011. p. 100.

15 SARLET, Ingo Wolfgang. A eficácia dos direitos fundamentais. 12 ed. Porto Alegre: Livraria do Advogado, 2014. p. 467, que se alinha à primeira vertente. 
lidade da medida retroativa ${ }^{16}$, ou, ainda melhor, não progressiva. Nesse diâmetro, o contra-argumento à deverosidade estatal nos limites da nomeada reserva do possível surge quando a escassez de recursos salta aos olhos, obrigando o redimensionamento do dever de progressividade. Desse modo, deflui-se que a hipótese de um regredir estatal só é justificável quando o Poder Público comprova "a falta efetiva dos recursos indispensáveis à satisfação dos direitos a prestações, assim como [a] eficiente aplicação dos mesmos"17.

Não passa despercebido o fato de o constituinte brasileiro ter renunciado à previsão de enunciado normativo que proíba a reversibilidade dos direitos fundamentais e ordene a progressividade, em que pese a importância que as categorias exercem enquanto freios ante a potencial "erosão das normas de direitos fundamentais"18. Além da ausência de uma previsão geral, também quando se propõe a aclarar os deveres correlatos aos direitos fundamentais em espécie, deixa de fazer qualquer alusão específica ao preceito. É isso que se verifica relativamente ao direito à educação, previsto no artigo 6ํㅜ da CF entre os designados direitos sociais, e no complexo normativo que se estende do artigo 205 ao artigo 214, o qual cuida de pormenorizar os deveres estatais relativos àquele direito, reconhecendo, em termos gerais, que a educação é direito de todos, ao mesmo passo que constitui dever do Estado (CF, artigo 205), sem, contudo, remissão a deveres específicos de não regressão da escala de satisfação deste direito e de progressividade.

16 SARLET, Ingo Wolfgang. A eficácia dos direitos fundamentais. 12 ed. Porto Alegre: Livraria do Advogado, 2014. p. 472.

17 SARLET, Ingo Wolfgang. FIGUEIREDO, Mariana Filchtiner. Reserva do Possível, Mínimo Existencial e Direito à Saúde: algumas aproximações. Revista da Defensoria Pública, ano 1, jul/dez, 2008. p. 205.

18 Expressão consagrada, no Brasil, por SARLET, Ingo Wolfgang. A eficácia dos direitos fundamentais. 12 ed. Porto Alegre: Livraria do Advogado, 2014. p. 413. 
Desta invisibilidade constitucional não decorrem consequências de cariz negativo. Dito de outra maneira, podendo-se extrair do texto constitucional deveres implícitos ou não positivados ${ }^{19}$, é cabível assentir quanto à existência de uma vedação de reversibilidade e uma ordenação de progressividade dos direitos fundamentais, em geral, e - ao que aqui revela importância - do direito à educação, em particular.

É sabido que a consecução de políticas públicas para a satisfação de direitos fundamentais implica custos. Para o financiamento dos direitos, arvora-se o Estado do poder arrecadatório que lhe confere a Constituição Federal por intermédio de normas de natureza tributária. Trata-se do que, no sentir de Cristina Pauner Chulvi, converte-se no dever constitucional de contribuir com a sustentação dos gastos públicos, ou, ainda, na responsabilidade cidadã com a manutenção do Estado e com a sua obrigação de redistribuição de renda e riqueza ${ }^{20}$. Esse ciclo, que principia com a contribuição e perpassa a arrecadação, culmina no dever estatal de decidir o quanto e o como necessários para a implementação de direitos. Ocorre que esse cenário decisório é insuperavelmente marcado por um grau de escassez, razão pela qual decidir sobre direitos fundamentais é sempre enfrentar tradeoffs, isto é, fazer escolhas conflitantes, na medida em que tão logo solucionam um problema, criam outros ${ }^{21}$. No mesmo sentido, é comum dizer-se que opções nessa seara são sempre trágicas - na expressão cunhada por Calabresi e Bobbitt -, pois

19 SARLET, Ingo Wolfgang. A eficácia dos direitos fundamentais. 12 ed. Porto Alegre: Livraria do Advogado, 2014. p. 236-7.

20 PAUNER CHULVI, Cristina. El deber constitucional de contribuir al sostenimiento de los gastos públicos. Disponível em: <http://www.tdx.cat/bitstream/handle/10803/10429/ pauner.pdf;jsessionid=7F07818855EF3BE803FB5001A45E3AF8.tdx2? sequence=1>. Acesso em: 02 nov. 22 . p. 78.

21 MANKIW, N. Gregory. Introdução à economia. São Paulo: Thomson Learning, 2006. p. 2006, [n.1]. 
que ocasionalmente "implicam a negação de direitos"22, sendo o objeto de uma política pública o resultado de uma combinação entre um grau de não realização de um direito e a necessidade de realização de um mínimo irrenunciável pelo caminho menos ofensivo ${ }^{23}$.

A dificuldade das decisões alocativas centra-se no conflito, que é perene, entre a não limitação das necessidades, a limitação de recursos e, ainda por cima, a onerosidade da aplicação dos recursos arrecadados ${ }^{24}$. Apesar disso, curiosamente, a consideração da escassez como uma constante invariavelmente atrelada à noção de direitos não recebeu toda a atenção, pelo menos na seara constitucional. Não é descabido supor que a explicação para isso tenha origem em um justificado temor de fragilização dos direitos fundamentais, até o ponto de, radicalmente, só ser possível falar nestes "onde há fluxo orçamentário que o permita"25. Contudo, ao revés do que possa parecer, assumir a escassez como fato tem o condão de pôr às claras os limites e possibilidades da tomada de decisões envolvendo direitos fundamentais no âmbito público.

Soma-se à escassez como fato a igualmente inconteste relevância do direito à educação, que torna não demasiado afirmar, como o faz Canotilho, que tal direito constitui verdadeiro pressuposto de exercício de outros direitos fundamentais ${ }^{26}$, isto é, a sua proteção serve a um fim específico, qual seja "formar o seu titular para o exercício de direitos fundamentais, permitindo que

22 AMARAL, Gustavo. Direito, Escassez e Escolha: em busca de critérios jurídicos para lidar com a escassez de recursos e as decisões trágicas. Rio de Janeiro: Renovar, 2001. p. 81.

23 CALABRESI, Guido; BOBBITT, Philip. Tragic choices. New York: Norton, 1932. p. 149.

24 Assim, ROSSETTI, José Paschoal. Introdução à economia. 20 ed. São Paulo: Atlas, 2012. p. 207.

25 GALDINO, Flávio. Introdução à teoria dos custos dos direitos: direitos não nascem em árvores. Rio de Janeiro: Lumem, 2005. p. 204, referindo-se à tese de Sustein e Holmes quanto aos custos dos direitos.

${ }^{26}$ CANOTILHO, José Joaquim Gomes. Direito constitucional e teoria da constituição. 7 ed. Coimbra: Almedina: 2003. p. 473. 
seja ele próprio a decidir seu futuro (...) [sendo a educação] um direito a serviço da liberdade e da autonomia do educando" 27. Tendo em conta a sua importância, há quem o eleve à condição de direito mínimo para uma vida condigna ${ }^{28}$, o que o faz parte da noção de mínimo existencial, sendo este o conjunto das "condições mínimas de existência humana digna que não pode ser objeto de intervenção do Estado [...] e que ainda exige prestações estatais positivas, [sendo certo que] sem o mínimo necessário à existência cessa a possibilidade de sobrevivência do homem e desaparecem as condições iniciais de liberdade"29.

Neste cenário, há de ser compreensível a presença, na Constituição Federal, de normas de caráter dirigente relativas ao direito à educação, como o é o artigo 212, que determina a aplicação anual, pela União e pelos Estados, Distrito Federal e Municípios, de, respectivamente, pelo menos, dezoito e vinte e cinco por cento da arrecadação de impostos na manutenção e desenvolvimento do ensino. 0 delineamento da atuação estatal para o futuro denota, nestes termos, a preocupação constitucional com os limites do exercício do poder deliberativo estatal quanto ao direito à educação.

27 ÁLVAREZ ÁLVAREZ, Leonardo. La educación en el Estado social y democrático de derecho. El ideário educativo em la Constitución Española. In: SARLET, Ingo Wolfgang; PRESTO LINERA, Miguel Ángel (Ed.). Los derechos sociales como instrumento de emancipación. Navarra: Aranzadi, 2010. p. 213.

28 Nesse sentido, afirma-se: "O direito à educação fundamental é um elemento do mínimo existencial, compondo o núcleo da dignidade humana e, portanto, sendo oponível aos poderes constituídos. Imaginar que seu atendimento possa ficar na dependência exclusiva da ação, e dos humores, do Executivo - em equipar sua rede de ensino de maneira conveniente - e do Legislativo - em dispor sobre a concessão de bolsas de estudo em instituições privadas - é tornar totalmente sem sentido tudo que sem expôs até aqui, assim como o próprio Estado de direito constitucional. Ao Judiciário compete tutelar o mínimo existencial e isso pelos meios substitutivos que forem necessários e aptos para atingir tal fim", BARCELLOS, Ana Paula. A eficácia jurídica dos princípios constitucionais: o princípio da dignidade da pessoa humana. 2. ed. Rio de Janeiro: Renovar, 2008. p. 298.

29 TORRES, Ricardo Lobo. O mínimo existencial como conteúdo essencial dos direitos fundamentais. In: SOUZA NETO, Cláudio Pereira de Souza; SARMENTO, Daniel. Direitos sociais: fundamentos, judicialização e direitos sociais em espécie. Rio de Janeiro, Lumem, 2008. p. 313-314. 
Encima-se a teoria do dirigismo constitucional na premissa de que o legislador não pode conformar direitos de qualquer $\operatorname{modo}^{30}$, o que, na lembrança de Gilberto Bercovici, não é o mesmo que afirmar que o programa constitucional tolhe a liberdade de conformação legislativa ou a discricionariedade do Governo ${ }^{31}$. Ao mesmo passo que as tarefas estatais se configuram como tarefas constitucionais ${ }^{32}$, a Constituição consagra-se em sua função de ordem, caracterizando-se como ordem fundamental ${ }^{33}$, o que, longe de desaguar em ingovernabilidade por enfitamento das decisões políticas $^{34}$, mostra-se contumaz, ainda no contexto brasileiro, para assegurar a realização de direitos fundamentais ${ }^{35}$.

No sentir de Bernd Schulte, a obrigação de garantia do efetivo uso dos direitos por seus titulares afeta o Estado de maneira a torná-lo necessário promovedor de intervenções sociais ${ }^{36}$. É justamente nessa conjuntura que também se enleva o condi-

30 COUTINHO, Jacinto Nelson de Miranda. Canotilho e a constituição dirigente. 2 ed. Rio de Janeiro: Renovar, 2005. p. 15.

31 BERCOVICI, Gilberto A problemática da Constituição dirigente: algumas considerações sobre o caso brasileiro. Revista de Informação Legislativa. Brasília. v. 36, n. 142, abr/jun, 1999. p. 40.

32 CANOTILHO, José Joaquim Gomes. Constituição dirigente e vinculação do legislador: contributo para a compreensão das normas constitucionais programáticas. 2 ed. Coimbra: Coimbra, 2001. p. VIII-XV.

33 CAnOTILHO, José Joaquim Gomes. Constituição dirigente e vinculação do legislador: contributo para a compreensão das normas constitucionais programáticas. 2 ed. Coimbra: Coimbra, 2001. p. 148.

340 que seria, em verdade, causado pelo que Bercovici chama de constituição dirigente invertida, BERCOVICI, Gilberto; MASSONETTO, Luís Fernando. A constituição dirigente invertida: a blindagem da constituição financeira e a agonia da constituição econômica. Sep. do Boletim de Ciências Económicas, Coimbra, v. XLIX, 2006. p. 18-19.

35 Sem adentrar as discussões sobre os termos de sobrevida do dirigismo constitucional no Brasil, cuida-se, no presente, de assentir com a pertinência de sua aceitação, no sentido do defendido em SARLET, Ingo Wolfgang. A eficácia dos direitos fundamentais. 12 ed. Porto Alegre: Livraria do Advogado, 2014. p. 266, [n. 67].

36 SCHULTE, Bernd. Direitos fundamentais, segurança social e proibição de retrocesso. In: SARLET, Ingo Wolfgang (Org.). Direitos fundamentais sociais: estudos de direito constitucional, internacional e comparado. Rio de Janeiro: Renovar, 2003. p. 302-3. 
cionamento fiscal ${ }^{37}$ dos direitos, a prospecção de estratégicas de blindagem contra o seu esvaziamento e de promoção da sua máxima eficácia e efetividade.

\section{A PROTEÇÃO JURÍDICA DA EDUCAÇÃO ENQUANTO DIREITO SOCAL NO BRASIL}

\subsection{Federalismo e competências constitucionais para a con- secução de metas em matéria de educação \\ Nos termos do artigo 23, inciso $\mathrm{V}$, da CF, cabe à União, aos} Estados, ao DF e aos Municípios proporcionar os meios de acesso à educação. Trata-se de competência comum de natureza administrativa fixada no realce de um federalismo cooperativo, como de sorte tem se afigurado o modelo de Estado brasileiro. Digna de nota, neste ponto, é a lição de Raul Machado Horta no sentido de que "a competência comum condensa preceitos e recomendações dirigidas à União, aos Estados, ao Distrito Federal e aos Municípios, traduzindo intenções programáticas do constituinte"38 a serem executadas, nos ternos do parágrafo único do mesmo dispositivo, na medida da colaboração entre os entes federativos, com vistas ao equilíbrio do desenvolvimento e do bem-estar social, a qual deve ser fixada por legislação complementar. Ressalte-se que, na linha do artigo 211 da CF, a colaboração entre os entes federativos se dará pela atribuição de responsabilidade à União quanto à organização do sistema federal de ensino, aos Municípios quanto ao fomento do ensino fundamental e da educação infantil e aos Estados e ao Distrito Federal quanto à promoção do ensino fundamental e médio, tudo na condição de esfera de responsabilidade principal, mas não exclusiva, sob pena de contradição em face do dever de cooperação instituído.

37 Na expressão de CONTRERAS PELÁEZ, Francisco. Derechos sociales: teoría e ideologia. Madrid: Tecnos, 1994. p. 112.

38 HORTA, Raul Machado. Direito constitucional. 4 ed. Belo Horizonte: DelRey, 2003. p. 355 
É de recordar que o equacionamento da atuação dos entes federativos é realizado desde a premissa da predominância do interesse ${ }^{39}$, cabendo à União o pertinente ao interesse geral, aos Municípios o que se aproxima ao interesse local, e aos Estados os assuntos de afetação regional ou residual. A atuação coordenadora da União em matéria educacional é retirada, notadamente, do artigo 24, IX da CF, que, combinado com as regras de interpretação das competências concorrentes fixadas pelos parágrafos $1^{\circ}$ a $4^{\circ}$ do mesmo dispositivo, revela a atribuição do ente federativo para a edição de normas gerais afeitas à educação e o poder concorrente dos Estados, DF e Municípios no campo da suplementação complementar ou supletiva, se for o caso. A par disso, registre-se que também o artigo 22 da CF, em seu inciso XXIV, ateado ao estabelecimento de competências privativas da União, remete ao ente o poder de edição das diretrizes e bases da educação nacional. Se é verdade que se trata de patente exemplo de impropriedade técnica do sistema de competências brasileiro, como quer Fernanda Dias Menezes ${ }^{40}$, também é de lembrar que, no campo das dispersões normativas no que toca aos poderes normativos em matéria de educação, também em outro lugar, e de forma aparentemente redundante, firma a Constituição a competência para estabelecer o Plano Nacional de Educação, de duração decenal, arrimado em regime de colaboração entre os entes federativos (artigo 214), sendo que na mesma esteira dispõe o artigo 9o. I da Lei de Diretrizes e Bases da Educação Nacional, que, contudo, expressamente incumbe a União de cria-lo, ao mesmo tempo que diz que esta elaboração deverá contar com a colaboração dos Estados, DF e Municípios. A criação de Planos dessa natureza é, como lembra Maria Paula Dallari Bucci, “a ex-

39 BARACHO JÚNIOR, José Alfredo de Oliveira et al. O Estado Democrático de Direito e a necessária reformulação das competências materiais e legislativas dos Estados. Revista de Informação Legislativa. Brasília, a. 47, n. 186, abr./ jun. 2010, p. 157.

40 ALMEIDA, Fernanda Dias Menezes. Competências na Constituição de 1988. 5 ed. São Paulo: Atlas, 2010. p. 97 e seq. 
pressão mais frequente das políticas públicas (...) [nas quais] se estabelecem os objetivos da política, suas metas temporais, os instrumentos os instrumentos institucionais de sua realização e outras condições de implementação" ${ }^{41}$.

Neste contexto, comporta remeter à recente promulgação da Lei no 13.005/2014, que institui o Plano Nacional vigente, após quatro anos de tramitação no Congresso Nacional e um interstício temporal de três anos em relação ao período de vigência prospectado para o Plano anterior. Acobertadas no PL noㅜ 8.035/2010, vinte metas multidimensionais e suas respectivas estratégias de concretização se justificaram enquanto "movimento coletivo de construção política e programática, [marcado por] uma visão sistêmica da educação que abarque todas as etapas e modalidades da educação de maneira integrada, a fim de que elas se reforcem reciprocamente e desencadeiem um ciclo virtuoso de investimento em educação" 42 [sic.]. Após a apresentação de substitutivos na Câmara e no Senado, redefinição de metas e realocação de estratégias, a redação final aprovada firma compromissos acerca do(a) 1. Educação infantil, 2. Ensino fundamental, 3. Ensino Médio, 4. Educação especial e inclusiva, 5. Alfabetização, 6. Educação integral, 7. Aprendizado adequado na idade certa, 8. Escolaridade média, 9. Alfabetização e alfabetismo funcional de jovens e adultos, 10. Educação de jovens e adultos integrada à educação profissional, 11. Educação profissional, 12. Educação superior, 13. Titulação de professores da educação superior, 14. Pós-graduação, 15. Formação de professores, 16. Formação continuada e pós-graduação de professores, 17. Valorização do

41 BUCCI, Maria Paula Dallari. Políticas públicas e direito administrativo. Revista de Informação Legislativa. Brasília, a. 34, n. 133, jan./mar, 1997. p. 95.

42 PL 8.035/2010 - CONGRESSO NACIONAL. Disponível em: < http://www2. camara.leg.br/atividadelegislativa/comissoes/comissoes-temporarias/especiais/54a-legislatura/pl-8035-10-plano-nacional-deeducacao >. Acesso em: 12 out. 2014. p. 31. Sítio no qual se pode encontrar, ainda, toda a tramitação do PL até a sua conversão na supracitada lei. 
professor, 18. Plano de carreira docente, 19. Gestão democrática e 20. Financiamento da educação $0^{43}$.

Se tudo isto se erige tomando em conta a repartição de competências desenhada na Constituição, a atuação dos entes federados importa uma coordenação permanente de modo a não subtrair responsabilidades e encampar esforços conjugados perante metas que são facialmente complexas. De tal sorte, é preciso sublinhar, como o faz Nina Ranieri, que suportar encargos obriga simultaneamente pensar em receitas ${ }^{44}$. Para Daniel Cara e Luiz Araújo, desde a proposta inicial apresentada ao Congresso, há um ocultamento do problema do financiamento da educação brasileira, o que se percebe, primeiramente, com a ausência de qualquer diagnóstico ou planilha de custos na proposição normativa. Ainda lembram que só após o início da tramitação do Projeto de Lei é que o Ministério da Educação apresentou o "PNE 2011-2020: metas e estratégias" e o "Previsão de investimento necessário para cumprir o PNE, além do investimento atual de 5\% do PIB", ambos documentos orientadores das matrizes do Plano e do volume de recursos a serem dispendidos para a sua realização $0^{45}$.

A despeito da crítica, não parece ser outra a finalidade da Meta 20 do PNE, que atenta exatamente ao tema do financiamento dos programas educacionais ao fixar o compromisso de "ampliar o investimento público em educação pública de forma a atingir, no mínimo, o patamar de 7\% (sete por cento) do Produto Interno Bruto - PIB do País no 5o (quinto) ano de vigência desta Lei e, no mínimo, o equivalente a $10 \%$ (dez por cento) do PIB ao

43 Para o acompanhamento contínuo das metas, remete-se ao OBSERVATÓRIO do PNE. Disponível em: < http://www.observatoriodopne.org.br/>. Acesso em: 12 out. 2014.

44 RANIERI, Nina. Os Estados e o direito à educação na Constituição de 1988: comentários acerca da jurisprudência do Supremo Tribunal Federal. In: RANIERI, Nina (Coord.). Direito à educação: aspectos constitucionais. São Paulo: Edusp, 2009. p. 44.

45 ARAÚJO, Luiz; CARA, Daniel. O financiamento do PNE II. In: MANHAS, Cleomar (Org.). Quanto custa universalizar o direito à educação?. Brasília: Instituto de Estudos Socioeconômicos, 2011. p. 67-8. 
final do decênio". Entre as estratégias guindadas, destacam-se a garantia de fontes de financiamento permanente e sustentáveis (20.1), a criação de lei complementar, na esteira do demandado pelo artigo 23, parágrafo único da CF, para a cooperação entre União, Estados, DF e Municípios (20.9) e a destinação de parcela da participação no resultado ou da compensação financeira pela exploração de petróleo e gás natural e outros recursos à manutenção e desenvolvimento do ensino, a ser acrescida ao já vinculado recurso inserto no artigo 212 da CF $(20.3)^{46}$.

Na conjuntura do marco legal da política educacional, tem-se que o concernente ao nicho das competências federativas e ao financiamento da atuação dos entes federados constitui importante e primacial aporte à satisfação do direito à educação no Brasil. Se os contornos que traçam a Constituição Federal e, mais recentemente, o PNE, se afigurarem viabilizadores do cumprimento das metas tracejadas, será acertado ressaltar que o caráter programático das normas relativas à educação não gravou de inocuidade a atuação estatal, afinando-se, a bem dizer, ao dever de satisfação maximizada do direito.

${ }^{46}$ A regulamentação da destinação de receitas do pré-sal para as áreas de educação e saúde se dá pela Lei dos Royalties - Lei no 12.858/2013, que, precisamente em seu artigo $2^{\circ}$, $§ 3^{\circ}$, dispõe: “União, Estados, Distrito Federal e Municípios aplicarão os recursos previstos nos incisos I e II deste artigo no montante de $75 \%$ (setenta e cinco por cento) na área de educação e de $25 \%$ (vinte e cinco por cento) na área de saúde" [grifamos]. Ressalta-se também o artigo 4º, que carrega o mencionado na Estratégia 20.3 do PNE quanto à adição dos recursos dos royalties aos vinculados no artigo 212 da CF: "Os recursos destinados para as áreas de educação e saúde na forma do art. $2^{2}$ o serão aplicados em acréscimo ao mínimo obrigatório previsto na Constituição Federal". Para além disso, já a Lei do pré-sal - Lei no 12.351/2010 havia criado, em seu artigo 47, o Fundo Social - FS do pré-sal, com a finalidade de constituir fonte de recursos para o desenvolvimento social e regional, na forma de programas e projetos na área da educação (inciso I). 


\subsection{Arquitetura das posições jusfundamentais protegidas na} Constituição Federal

O plexo de posições juridicamente protegidas no texto constitucional relativas à educação verbera a conveniência de se falar em um direito geral à educação do qual é possível extrair condutas de distintos matizes. Sendo este um direito de faceta preponderantemente positiva, a expectativa principal gerada por sua positivação é de uma atuação comissiva por parte do Estado, notadamente com a finalidade de protegê-lo e promovê-lo. A par e concomitantemente, extraem-se também dele expectativas negativas, quais sejam as assim designadas liberdades sociais em matéria de educação, a exemplo das liberdades de aprender, ensinar, pesquisar e divulgar o pensamento, reunidas no artigo 206, II.

Compreender o direito à educação como um todo é, desta maneira, assimilar as relações entre os seus titulares e destinatários em esquadras distintas, mas sem operar qualquer sorte de clivagem tendente a imprimir um regime de tutela que privilegie alguma de suas dimensões a despeito de outras. Isso significa adotar um regime único de tutela da educação, o que não importa invizibilizar diferenças a depender de seu campo de incidência e pretensões geradas.

No âmbito público, isto é, no espaço de condução estatal da implementação do direito - que é, sublinha-se, o que importa nesta oportunidade ${ }^{47}$ - prevê a Constituição, em seu artigo 205, que é dever do Estado a promoção da educação visando ao pleno desenvolvimento da pessoa, seu preparo para o exercício da cidadania e sua qualificação para o trabalho ${ }^{48}$. 0 mesmo enun-

47 Lembra-se, contudo, que a incidência privada do direito à educação é uma previsão expressa da Constituição, em seu artigo 209, segundo o qual: "0 ensino é livre à iniciativa privada, atendidas as seguintes condições: I - cumprimento das normas gerais da educação nacional; II - autorização e avaliação de qualidade pelo Poder Público". O não tratamento do tema nessa esfera justifica-se, exclusivamente, por questões metódicas atreladas ao recorte da abordagem.

48 A definição do tipo de educação a ser fornecida qualifica a prestação estatal, que deve ser apta a desenvolver a autonomia do indivíduo (pleno desenvol- 
ciado é imperativo na definição da titularidade, assegurando tratar-se de direito de todos. No que diz com esta última, há que compreender que, com a expressão, o constituinte lança mão da titularidade simultaneamente individual e coletiva do direito à educação, que o faz exigível nas duas dimensões, ainda que penda uma preferência por aquela última ${ }^{49}$. 0 estiramento disso é que o Estado investe-se nos deveres de promoção do direito à educação mediante políticas públicas, prioritariamente, visando o atingimento de uma coletividade, ao mesmo passo em que a ele compete atender, de alguma maneira, demandas individuais judicializáveis. Outro não poderia, aliás, ser o entendimento extraído mesmo do artigo 5ํㅜ, caput, que dispõe sobre a titularidade dos direitos fundamentais, ainda que, especialmente em razão do fato custo, tão caro à disciplina dos direitos sociais, "a titularidade individual [destes] esteja atualmente associado ao assim designado direito (e garantia) ao mínimo existencial, por sua vez, fundado essencialmente na conjugação entre o direito à vida e o princípio da dignidade da pessoa humana, e que, precisamente por esta fundamentação, não pode ter sua titularidade individual afastada, por dissolvida numa dimensão coletiva" ${ }^{50}$. No mais, para Nina Ranieri, a Constituição ainda alarga a titularidade do direito à educação a grupos de pessoas indeterminadas, como as gerações futuras, especialmente a partir "do art. 210 (relativo

vimento da pessoa), capacitar à participação democrática (preparo para o exercício da cidadania) e fornecer preparo profissional (qualificação para o trabalho). Assim, cf. MALISKA, Marcos Augusto. $O$ direito à educação e a Constituição. Porto Alegre: Sérgio Fabris, 2001. p. 160-1.

49 Pelos argumentos que se apresentam ao direito à saúde em SARLET, Ingo Wolfgang. A titularidade simultaneamente individual e transindividual dos direitos sociais analisada à luz do exemplo do direito à proteção e promoção da saúde. Direitos fundamentais e justiça. ano 4. n. 10. jan/mar, 2010. p. 205229 e podem, sem qualquer distorção, ser transportados para a educação.

50 SARLET, Ingo Wolfgang. A titularidade simultaneamente individual e transindividual dos direitos sociais analisada à luz do exemplo do direito à proteção e promoção da saúde. Direitos fundamentais e justiça. ano 4. n. 10. jan/mar, 2010. p. 216. 
aos conteúdos mínimos para o ensino fundamental, de maneira a assegurar formação básica comum e respeito aos valores culturais e artísticos, nacionais e regionais), e de seu $\S 2^{\circ}$ (que, como exceção à regra geral de utilização da língua portuguesa no ensino fundamental, assegura às comunidades indígenas a utilização de línguas maternas)" 51 .

Quanto aos deveres estatais, além da referência a um dever geral no artigo 205, expresso e correlato, a Constituição insere no artigo 208 um conjunto de deveres fundamentais específicos e de caráter prestacional. Vejam-se, neste particular, os deveres a) de educação básica obrigatória e gratuita dos 4 (quatro) aos 17 (dezessete) anos de idade, assegurada inclusive sua oferta gratuita para todos os que a ela não tiveram acesso na idade própria; b) de progressiva universalização do ensino médio gratuito; c) de atendimento educacional especializado aos portadores de deficiência, preferencialmente na rede regular de ensino; d) de educação infantil, em creche e pré-escola, às crianças até 5 (cinco) anos de idade; e) de acesso aos níveis mais elevados do ensino, da pesquisa e da criação artística, segundo a capacidade de cada um; f) de oferta de ensino noturno regular, adequado às condições do educando e g) de atendimento ao educando, em todas as etapas da educação básica, por meio de programas suplementares de material didático-escolar, transporte, alimentação e assistência à saúde. Esta enumeração de deveres torna incontroversa a existência de um direito público subjetivo (CF, artigo 208, $\S 1^{\circ}$ ), que corrobora a possibilidade de exigibilidade individual e coletiva daquele direito perante a não-oferta e permite a responsabilização da autoridade competente por omissão (CF, artigo 208, §ํㅜ).

51 RANIERI, Nina. Os Estados e o direito à educação na Constituição de 1988: comentários acerca da jurisprudência do Supremo Tribunal Federal. In: RANIERI, Nina (Coord.). Direito à educação: aspectos constitucionais. São Paulo: Edusp, 2009. p. 45. 
Para além de tais disposições constitucionais, importa lembrar que um direito de viés prestacional se desmembra também em exigências de organização e procedimento, materializadas em regras para a obtenção de um resultado conforme direitos fundamentais ${ }^{52}$. No tocante ao direito à educação, se alocam nesta categoria, por exemplo, a garantia da autonomia universitária, prevista no artigo 207, a criação do Plano Nacional de Educação, no artigo 214, e a vinculação de receitas públicas com finalidade definida pela Constituição em seu artigo 212.

\section{VINCULAÇÃO CONSTITUCIONAL DE RECEITA MÍNIMA PARA A SATISFAÇÃO DO DIREITO À EDUCAÇÃO NO BRASIL: UMA LEITURA DO ARTIGO 212 DA CONSTITUIÇÃO FEDERAL EM CONFORMIDADE COM O DEVER DE PROGRESSIVIDADE RELATIVO AOS DIREITOS SOCIAIS}

Na seara do financiamento do direito à educação, o Título VII da Lei de Diretrizes e Bases da Educação Nacional dispõe sobre os recursos públicos que se prestam a fornecer condições de exercício das competências constitucionais administrativas dos entes federados no pertinente à matéria. Ademais, configuram as normas ali ajuntadas concreções do texto constitucional, que, de maneira geral, refere-se ao custeio da educação em seus artigos 212 e 213 .

Segundo o artigo 68 da LDB, a origem dos recursos destinados à educação encontra-se a) na receita de impostos próprios da União, dos Estados, do Distrito Federal e dos Municípios; b) na receita de transferências constitucionais e outras transferências; c) na receita do salário-educação e de outras contribuições

52 Assim, ALEXY, Robert. Teoria dos direitos fundamentais. São Paulo: Malheiros, 2008. p. 473. 
sociais; d) na receita de incentivos fiscais; cabendo, ainda, a instituição de outras fontes de financiamento por meio de lei ${ }^{53}$.

Para assegurar a concretização da tarefa constitucional, o constituinte lança mão da técnica de vinculação de receitas, ordenando que, no mínimo, 18\% por cento, no âmbito da União, e 25\%, no âmbito dos Estados, DF e Municípios da receita resultante de impostos, compreendida a proveniente de transferências seja direcionada para a manutenção e desenvolvimento do ensino. 0 artigo 69 da LDB reproduz o substrato do que é disposto no artigo 212 da CF com a seguinte redação: "A União aplicará, anualmente, nunca menos de dezoito, e os Estados, o Distrito Federal e os Municípios, vinte e cinco por cento, ou o que consta nas respectivas Constituições ou Leis Orgânicas, da receita resultante de impostos, compreendidas as transferências constitucionais, na manutenção e desenvolvimento do ensino público", sendo que o que se deve e o que não se deve compreender por despesas para a manutenção e desenvolvimento do ensino está elencado nos subsequentes artigos 70 e 71 , respectivamente.

Note-se, neste particular, que a LDB alude à possibilidade de outros percentuais serem fixados nas esferas estadual e municipal, por meio de Constituições e Leis Orgânicas. Se tomada de empréstimo a noção de simetria constitucional como geradora de um dever de observação obrigatória da sistemática ditada

53 No âmbito das contribuições sociais as quais se refere o artigo 149 da CF, destaca-se aquela disciplinada pela Lei no 10.168/2000, nomeada CIDE-Tecnologia, cujo fim é financiar o Programa de estímulo à interação Universidade-empresa para o apoio à inovação. 0 realce aqui operado deve-se ao fato de a lei, no esteio da arrecadação para composição do Fundo Nacional de Desenvolvimento Científico e Tecnológico, fixar uma subvinculação mínima em seu artigo 6º , determinando que, "trinta por cento [dos recursos], no mínimo, serão aplicados em programas de fomento à capacitação tecnológica e ao amparo à pesquisa científica e ao desenvolvimento tecnológico nas regiões Norte, Nordeste e Centro-Oeste" [grifamos]. Tal opção, pensa-se, está adequadamente afinada especialmente com um dos objetivos da República Federativa do Brasil, quando seja a redução das desigualdades sociais e regionais (CF, artigo 3은 III). 
pela Constituição Federal ${ }^{54}$, então só se pode compreender tal dispositivo como autorizador de fixação de percentuais a maior, coibida a interpretação de suposta autorização da redução dos percentuais constitucionais, sob pena de afronta à própria Constituição Federal.

Para além da referida vinculação constitucional, cabe realçar a criação do Fundo de Manutenção e Desenvolvimento da Educação Básica e de Valorização dos Profissionais da Educação - Fundeb, por meio da EC no 53/2006, em substituição ao Fundo de Manutenção e Desenvolvimento do Ensino Fundamental e de Valorização do Magistério - Fundef, que vigorou de 1998 a 2006. Tal Fundo conduz à subvinculação de $20 \%$ - 5\% a mais que o antecessor Fundef, o qual se destinava exclusivamente à educação fundamental - das receitas dos impostos e transferências dos Estados, DF e Municípios vinculados à área educacional para a promoção de educação básica.

Os percentuais fixados pelo artigo 212 da CF foram objeto de discussão na Conferência Nacional de Educação - Conae, realizada em 2010. Por ocasião do encontro, aprovou-se a proposta de aumento dos percentuais mínimos de receitas provenientes de impostos, das taxas e contribuições sociais que União, Estados, DF e Municípios investem em educação para 25\%, no caso da União, e 30\%, no caso dos Estados, DF e Municípios. A proposta, que se voltava ao empreendimento de solucionar alguns dos pontos sensíveis da promoção do direito à educação no Brasil, entre os quais a atuação ainda insuficiente da União nos contornos da educação básica e a existência de um regime de colaboração falho entre os entes federativos, não foi, contudo, incorporada ao $\mathrm{PNE}^{55}$.

54 ARAÚJO, Marcelo Labanca Corrêa de. Jurisdição constitucional e federação: o princípio da simetria na jurisprudência do STF. Rio de Janeiro: Elsevier, 2009. p. 107.

55 CONAE - Documento final. Disponível em: <http://conae.mec.gov.br/images/ stories/pdf/pdf/ documentos/documento_final.pdf>. Acesso em: 17 out. 2014. p. 101 e seq. 
A vinculação de receitas provenientes de impostos constitui exceção ao princípio da não-afetação que rege o Direito Financeiro e se encontra expresso no artigo 167, IV da CF,

1 a parte - "São vedados (...) a vinculação de receita de impostos a órgão, fundo ou despesa", bem como, transversalmente, no artigo 4ํㅗㅇ II do Código Tributário Nacional - "A natureza jurídica específica do tributo é determinada pelo fato gerador da respectiva obrigação, sendo irrelevantes para qualificá-la: (...) a destinação legal do produto da sua arrecadação". Nessa linha é que, regra geral, o dever constitucional de contribuição é qualitativamente determinado, posto que se destina a satisfazer direitos fundamentais, mas quantitativamente indeterminado, sendo a quantia a gastar objeto de deliberação posterior ${ }^{56}$.

Na esteira de Torres, tal flexibilização à aludida regra, descambada pela vinculação, tem a "desvantagem de engessar o orçamento público, e, se não reservadas à garantia de direitos fundamentais, tornam-se meras políticas públicas indevidamente constitucionalizadas" 57 . Ainda no derredor do tema, importa lembrar que a Lei de Responsabilidade Fiscal - LC no 101/2000 fixou, em seu artigo 8oㅗ parágrafo único, que "os recursos legalmente vinculados a finalidade específica serão utilizados exclusivamente para atender ao objeto de sua vinculação, ainda que em exercício diverso daquele em que ocorrer o ingresso".

Considerado o fim legítimo de satisfação dos direitos sociais, no âmbito da Conae, ressaltou-se precisamente a necessidade de revogar, de imediato, a Desvinculação de Receitas da União

56 PAUNER CHULVI, Cristina. El deber constitucional de contribuir al sostenimiento de los gastos públicos. Disponível em: <http://www.tdx.cat/bitstream/handle/10803/10429/ pauner.pdf;jsessionid=7F07818855EF3BE803FB5001A45E3AF8.tdx2?sequence=1 >. Acesso em: 02 nov. 2014. p. 153-4.

57 TORRES, Ricardo Lobo. Curso de Direito financeiro e tributário. 11 ed. Rio de Janeiro: Renovar, 2004. p. 118. 
- DRU para todas as áreas sociais ${ }^{58}$. A técnica de desvinculação de receitas é usada com o propósito de garantir maleabilidade administrativa com o aumento dos recursos de livre alocação, ditos ordinários, para, por exemplo, pagamento de juros da dívida pública, visando atingir as metas relativas ao superávit primário. Não são outras as razões a justificar a redação do artigo 76 do ADCT conferida pela EC no 68/2011 ${ }^{59}$, nos termos do qual "São desvinculados de órgão, fundo ou despesa, até 31 de dezembro de 2015, 20\% (vinte por cento) da arrecadação da União de impostos, contribuições sociais e de intervenção no domínio econômico, já instituídos ou que vierem a ser criados até a referida data, seus adicionais e respectivos acréscimos legais". No que diz com a educação, convém recordar que a EC nº 59/2009 acrescentou o $\S 3^{\circ}$ ao artigo 76 a fim de reduzir o percentual da desvinculação anualmente, sendo que "para efeito do cálculo dos recursos para manutenção e desenvolvimento do ensino de que trata o art. 212 da Constituição, o percentual referido no caput deste artigo será de 12,5\% (doze inteiros e cinco décimos por cento) no exercício de 2009, 5\% (cinco por cento) no exercício de 2010, e nulo no exercício de 2011. Por esta razão é que na redação que empresta a EC no 68/2011 ao §3ํㅡ, "para efeito do cálculo dos recursos para manutenção e desenvolvimento do ensino de que trata o art. 212 da Constituição Federal, o percentual referido no caput será nulo". Note-se, ainda, que desde a sua origem a DRU manteve-se ao largo da contribuição social do salário-educação destinado à

58 CONAE - Documento final. Disponível em: <http://conae.mec.gov.br/images/ stories/pdf/pdf/ documentos/documento_final.pdf $>$. Acesso em: 17 out. 2014. p. 101 e seq.

${ }^{59}$ As precedências normativas estão na EC no 27/2000, que instituiu a DRU através da inclusão do artigo 76 no ADCT, com vigência no período de 2000 a 2003, e na EC no 56/2007, que prorrogou esse período até 31 de dezembro de 2011. Antes disso, contudo, lembra Fernando Facury Scaff que na condição de antecedentes da DRU estão o Fundo Social de Emergência - FSE e o Fundo de Estabilização Fiscal. Para análise particular de cada um, cf. SCAFF, Fernando Facury. Direitos humanos e desvinculação das receitas da União - DRU. Revista de direito administrativo. n. 236. Rio de Janeiro, abr./jun., 2004. p. 33-55. 
educação básica, no sentido contornado pelos artigos 212 , §5ํㅜ da CF e 76, §2을 do ADCT.

É de toda sorte importante assentar que a DRU é questionada em sua constitucionalidade quando em questão o financiamento de direitos sociais, sendo, por exemplo, para Scaff, uma efetiva violação à supremacia constitucional ${ }^{60}$, dado se tratar de uma opção do constituinte originário a destinação de receitas para a garantia de condições mínimas de vida digna. Dessa sorte, observa o autor, ainda, que mais comprometida fica a promoção de direitos sociais se tomado em conta que a DRU não foi acompanhada, em sua concepção originária, de nenhuma finalidade expressa quanto ao emprego dos recursos desvinculados, de maneira que não haveria obrigação de sua utilização em qualquer finalidade social específica ${ }^{61-62}$.

É incontroverso que constitui óbice à satisfação dos direitos sociais - e, particularmente, do direito à educação - a dívida pública nacional, e que a política de desvinculação enfileira-se,

60 SCAFF, Fernando Facury. Reserva do possível, mínimo existencial e direitos humanos. Verba Juris. ano 4, n. 4, jan./dez. 2005. p. 96. Em outra oportunidade, parece o autor se alinhar à tese de que a desvinculação de receitas não conduz necessariamente a um alvitramento da Constituição, embora seja o que tenha ocorrido devido ao contingenciamento irregular de recursos, SCAFF, Fernando Facury. Direitos humanos e desvinculação das receitas da União - DRU. Revista de direito administrativo. n. 236. Rio de Janeiro, abr./ jun., 2004. p. 48.

61 SCAFF, Fernando Facury. Direitos humanos e desvinculação das receitas da União - DRU. Revista de direito administrativo. n. 236. Rio de Janeiro, abr./ jun., 2004. p. 40.

62 Apensa-se, em linha contrária, a mensagem que acompanha a PEC $\mathrm{n}$ o 50/2007, para a progressão da DRU: "É importante ressaltar que a existência da DRU não tem impedido a expansão de programas sociais prioritários, a exemplo do bolsa-família e da ampliação das dotações destinadas à educação, que deverá prosseguir nos próximos anos com o Fundo de Manutenção e Desenvolvimento da Educação Básica e de Valorização dos Profissionais de Educação - FUNDEB. Ao contrário, a DRU tem permitido à administração pública estabelecer prioridades e alocar recursos para o atendimento dessas prioridades", EXPOSIÇÃO de motivos no 00046/2007 - MF/MP. Disponível em: <http://www.planalto.gov.br/ccivil_03/Projetos/EXPMOTIV/ EMI/2007/46\%20-\%20MF\%20MP.htm>. Acesso em: 19 out. 2014. 
também, junto ao propósito de sanar os seus juros. É tamanha a dimensão da dívida que, no diagnóstico de Paulo Caliendo, "existe uma reserva do possível geral no Brasil, que impede os gastos sociais"63. Se isso é certo, não menos relevante é destacar que a tributação tem igualmente, entre as suas funções, o alargamento da reserva do possível, fornecendo os elementos para a satisfação de direitos sociais, sendo que, no caso da educação, isto ocorre com as vinculações constitucionais correlatas, a instituição de incentivos fiscais e o uso da extrafiscalidade, destacando-se, neste último ponto, por exemplo, a possibilidade de dedução do imposto de renda das despesas com educação (educação básica, técnica e superior, o que engloba graduação e pós-graduação), no compasso do que já vem disposto desde o artigo 15 da Lei no 4.357/1964, bem como a imunidade tributaria fixada no artigo 150 , VI, c, reproduzido no artigo 9으, IV, c do Código Tributário Nacional, que abarca as instituições de educação sem fins lucrativos, assim concebidas aquelas que se enquadram no definido artigo 14 também desta lei. Diametralmente oposta e ensejadora da diminuição da reserva do possível é a prática de desvio de recursos para finalidades distintas à promoção de direitos socais, conduzida, a exemplo, pela desvinculação de receitas públicas da União ${ }^{64}$.

É sobre os mesmos fundamentos que se prospecta, aqui, a necessidade - e, se é assim, também a possibilidade - de uma leitura constitucionalmente adequada da vinculação de percentuais mínimos para a condução de políticas públicas educacionais empreendida pelo artigo 212 da CF. A fixação de um dever mínimo é compatível com o constitucionalismo dirigente, estabelecedor

63 CALIENDO, Paulo. Reserva do possível, direitos fundamentais e tributação. In: SARLET, Ingo Wolfgang; TIMM, Luciano Benetti (Orgs.). Direitos fundamentais: orçamento e reserva do possível. Porto Alegre: Livraria do Advogado, 2008. p. 202.

64 Tudo isso na esteira de CALIENDO, Paulo. Reserva do possível, direitos fundamentais e tributação. In: SARLET, Ingo Wolfgang; TIMM, Luciano Benetti (Orgs.). Direitos fundamentais: orçamento e reserva do possível. Porto Alegre: Livraria do Advogado, 2008. p. 206. 
da proteção e promoção máxima e progressiva dos direitos, se e estritamente quando compreendido em conjunto com o dever de reconhecimento da eficácia prima facie plena e aplicabilidade direta e imediata dos direitos fundamentais, assentada no $§ 1^{0}$ do artigo $5^{\circ}$ da $\mathrm{CF}^{65}$. Ora, se é verdade que há um dever de fundamentar a recusa a conferir a máxima efetividade às normas de direitos fundamentais, o dispositivo tenderia a fornecer um álibi, apto a tornar tal argumentação prescindível, posto que o cumprimento do mínimo é, ao mesmo tempo, a ocorrência da hipótese fática da norma. Contudo, em sentido oposto, e acertadamente, pode-se inferir que o artigo $5^{\circ}$, $\$ 1^{\circ}$ indica um processo de maximização da realização dos direitos, que acaba por situar o artigo 212 da CF como ponto de partida, e não de chegada.

No mais, se o dever de pagar tributos é uma espécie de dever fundamental autônomo que serve à satisfação de direitos ${ }^{66}$, não pode ser este um nicho a operar uma restrição enviesada ao direito à educação, limitando o quantum a ser despendido na sua realização. Disto decorre que a única interpretação compatível da vinculação constitucional de receita mínima com a dogmática dos direitos fundamentais é a que aqui se sublinha.

A progressividade que marca o dirigismo constitucional é, ademais, revelada em ações atuais voltadas ao aumento de investimentos na educação, como as já referidas metas afixadas no PNE, que determinam a destinação de $10 \%$ do PIB nacional para a educação, no prazo de dez anos, e a condução de parcela da participação ou compensação financeira pela exploração de petróleo e gás natural e outros recursos para o mesmo fim, fato que, aliás, corrobora o aqui disposto.

Por fim, se é bem verdade que a alocação progressiva de recursos para a educação não converge, necessariamente, para

65 SARLET, Ingo Wolfgang. A eficácia dos direitos fundamentais. 12 ed. Porto Alegre: Livraria do Advogado, 2014. p. 269 e seq.

66 SARLET, Ingo Wolfgang. A eficácia dos direitos fundamentais. 12 ed. Porto Alegre: Livraria do Advogado, 2014. p. 236-7. 
o aumento da qualidade e equidade das ações do ensino de que fala o $3^{\circ}$ o do artigo 212, certamente constitui premissa basilar para o atingimento delas, firmando-se enquanto sua condição de possibilidade.

\section{CONSIDERAÇÕES FINAIS}

0 compromisso firmado na Constituição no tocante à educação por ocasião da vinculação de receita mínima para a satisfação do direito é revelador da natureza dirigente das normas constitucionais que o assentam, bem como da importância conferida pelo constituinte originário à consecução de fins sociais. Presume-se que há efetivo benefício no atrelamento de receitas quando em questão um direito social, pois a destinação exclusiva importa garantia tendente a promover o direito.

Se esse é o fundamento para a vinculação de receita mínima no artigo 212 da CF, conclui-se que outra não poderia ser a interpretação de tal previsão que não aquela que pugna pela compreensão de que o dever estatal, em todos os níveis da Federação, não se esgota com a aplicação do quantum ali definido. 0 dever do Estado para com a educação de que fala o artigo 205 da CF é, assim, um dever de satisfação progressiva, sendo o mínimo apenas a fatia inegociável de sua promoção - o que não importa dizer que seja exclusivamente esta a parcela esperada.

Esse entendimento é suportado pelo designado dirigismo constitucional, tal como, e concomitantemente, pela noção de progressividade dos direitos sociais, da qual decorre a proibição de regressividade dos direitos. Também com fulcro no artigo 5ํㅜ $\S 1^{\circ}$ da $\mathrm{CF}$, isto quer dizer que compete à União, aos Estados, DF e Municípios a aplicação do mínimo em matéria de educação, do mesmo modo que compete a estes agraudar os investimentos nesta seara, sob pena de dissonância em relação ao projeto constitucional. 


\section{REFERÊNCIAS}

ABRAMOVICH, Victor; COURTIS, Christian. Direitos sociais são exigíveis. Porto Alegre: Dom Quixote, 2011.

ALEXANDRINO, José de Melo. Direitos fundamentais. Estoril: Princípia, 2007.

ALEXY, Robert. Teoria dos direitos fundamentais. São Paulo: Malheiros, 2008.

ALMEIDA, Fernanda Dias Menezes. Competências na Constituição de 1988. 5 ed. São Paulo: Atlas, 2010.

ÁLVAREZ ÁLVAREZ, Leonardo. La educación en el Estado social y democrático de derecho. El ideário educativo em la Constitución Española. In: SARLET, Ingo Wolfgang; PRESTO LINERA, Miguel Ángel (Ed.). Los derechos sociales como instrumento de emancipación. Navarra: Aranzadi, 2010. p. 209-232.

AMARAL, Gustavo. Direito, Escassez e Escolha: em busca de critérios jurídicos para lidar com a escassez de recursos e as decisões trágicas. Rio de Janeiro: Renovar, 2001.

ARAÚJO, Luiz; CARA, Daniel. O financiamento do PNE II. In: MANHAS, Cleomar (Org.). Quanto custa universalizar o direito à educação?. Brasília: Instituto de Estudos Socioeconômicos, 2011. p. 67-82.

ARAÚJO, Marcelo Labanca Corrêa de. Jurisdição constitucional e federação: o princípio da simetria na jurisprudência do STF. Rio de Janeiro: Elsevier, 2009.

BARACHO JÚNIOR, José Alfredo de Oliveira et al. O Estado Democrático de Direito e a necessária reformulação das competências materiais e legislativas dos Estados. Revista de Informação Legislativa. Brasília, a. 47, n. 186, abr./jun. 2010. p. 153-69.

BARCELLOS, Ana Paula. A eficácia jurídica dos princípios constitucionais: o princípio da dignidade da pessoa humana. 2. ed. Rio de Janeiro: Renovar, 2008.

BERCOVICI, Gilberto A problemática da Constituição dirigente: algumas considerações sobre o caso brasileiro. Revista de Informação Legislativa. Brasília. v. 36, n. 142, abr/jun, 1999. p. 35-51.

; MASSONETTO, Luís Fernando. A constituição dirigente invertida: a blindagem da constituição financeira e a agonia da constituição econômica. Sep. do Boletim de Ciências Económicas, Coimbra, v. XLIX, 2006. 
BRASIL. STF. ADI 4543 MC/DF, Rel. Min. Cármen Lúcia. Julgada em: 19.10.2011.

BUCCI, Maria Paula Dallari. Políticas públicas e direito administrativo. Revista de Informação Legislativa. Brasília, a. 34, n. 133, jan./mar, 1997. p. 89-98.

CALABRESI, Guido; BOBBITT, Philip. Tragic choices. New York: Norton, 1932.

CALIENDO, Paulo. Reserva do possível, direitos fundamentais e tributação. In: SARLET, Ingo Wolfgang; TIMM, Luciano Benetti (Orgs.). Direitos fundamentais: orçamento e reserva do possível. Porto Alegre: Livraria do Advogado, 2008. p. 195-208. 24

CANOTILHO, José Joaquim Gomes. Constituição dirigente e vinculação do legislador: contributo para a compreensão das normas constitucionais programáticas. 2 ed. Coimbra: Coimbra, 2001.

. Direito constitucional e teoria da constituição. 7 ed. Coimbra: Almedina: 2003.

CONAE - Documento final. Disponível em: <http://conae.mec.gov.br/ images/stories/pdf/pdf/ documentos/documento_final.pdf>. Acesso em: 17 out. 2014.

CONTRERAS PELÁEZ, Francisco. Derechos sociales: teoría e ideologia. Madrid: Tecnos, 1994.

COURTIS, Christian. La prohibición de regressividad em matéria de los derechos sociales: apuntes introductorios. In: COURTIS, Christian. $\mathrm{Ni}$ um paso atrás: la prohibición de regresividad em matéria de derechos sociales. Buenos Aires: Del Puerto, 2006. p. 3-52.

COUTINHO, Jacinto Nelson de Miranda. Canotilho e a constituição dirigente. 2 ed. Rio de Janeiro: Renovar, 2005.

EXPOSIÇÃO de motivos no 00046/2007 - MF/MP. Disponível em:

<http://www.planalto.gov.br/ccivil_03/Projetos/ EXPMOTIV/ EMI/2007/46\%20\%20MF\%20MP.htm>. Acesso em: 19 out. 2014.

GALDINO, Flávio. Introdução à teoria dos custos dos direitos: direitos não nascem em árvores. Rio de Janeiro: Lumem, 2005.

HORTA, Raul Machado. Direito constitucional. 4 ed. Belo Horizonte: DelRey, 2003. 
MALISKA, Marcos Augusto. $O$ direito à educação e a Constituição. Porto Alegre: Sérgio Fabris, 2001.

MANKIW, N. Gregory. Introdução à economia. São Paulo: Thomson Learning, 2006.

NOVAIS, Jorge Reis. As restrições aos direitos fundamentais não expressamente autorizadas pela constituição. Coimbra: Coimbra, 2003. 25

OBSERVAÇÃO geral no 13 do Pacto Interacional de Direitos Econômicos, Sociais e Culturais = OBSERVACIÓN general no 13 del Pacto Internacional de Derechos Económicos, Sociales y Culturales. Disponível em:

$<$ http://www.servindi.org/pdf/ObservacionesyRecomendaciones Generales.pdf $>$. Acesso em: 10 out. 2014.

OBSERVATÓRIO do PNE. Disponível em: <http://www.observatoriodopne.org.br/>. Acesso em: 12 out. 2014.

PAUNER CHULVI, Cristina. El deber constitucional de contribuir al sostenimiento de los gastos públicos. Disponível em: <http://www.tdx.cat/ bitstream/handle/10803/10429/ pauner.pdf;jsessionid=7F07818855EF 3BE803FB5001A45E3AF8.tdx2? sequence=1>. Acesso em: 02 nov. 2014.

PL 8.035/2010 - CONGRESSO NACIONAL. Disponível em: <http://www2. camara.leg.br/atividade-legislativa/comissoes/comissoestemporarias/ especiais/54a-legislatura/pl-8035-10-plano-nacional-de-educacao >. Acesso em: 12 out. 2014.

QUEIROZ, Cristina. O principio da não reversibilidade dos direitos fundamentais sociais. Coimbra: Coimbra, 2006.

RANIERI, Nina. Os Estados e o direito à educação na Constituição de 1988: comentários acerca da jurisprudência do Supremo Tribunal Federal. In: RANIERI, Nina (Coord.). Direito à educação: aspectos constitucionais. São Paulo: Edusp, 2009. p. 39-59.

SARLET, Ingo Wolfgang. A eficácia dos direitos fundamentais. 12 ed. Porto Alegre: Livraria do Advogado, 2014.

A titularidade simultaneamente individual e transindividual dos direitos sociais analisada à luz do exemplo do direito à proteção e promoção da saúde. Direitos fundamentais e justiça. ano 4. n. 10. jan/ mar, 2010. p. 205-229.

. Posibilidades y desafíos de un derecho constitucional común latinoamericano. Un planteamiento a la luz del ejemplo de la llamada 
prohibición de retroceso social. Revista de derecho constitucional europeo. n. 11, 2009. 26

; FIGUEIREDO, Mariana Filchtiner. Reserva do Possível, Mínimo Existencial e Direito à Saúde: algumas aproximações. Revista da Defensoria Pública, ano 1, jul/dez, 2008. p. 179-234.

SCAFF, Fernando Facury. Direitos humanos e desvinculação das receitas da União - DRU. Revista de direito administrativo. n. 236. Rio de Janeiro, abr./jun., 2004. p. 33-55.

. Reserva do possível, mínimo existencial e direitos humanos. Verba Juris. ano 4, n. 4, jan./dez, 2005. p. 79-104.

SCHULTE, Bernd. Direitos fundamentais, segurança social e proibição de retrocesso. In: SARLET, Ingo Wolfgang (Org.). Direitos fundamentais sociais: estudos de direito constitucional, internacional e comparado. Rio de Janeiro: Renovar, 2003. p. 301-332.

SILVA, Virgílio Afonso da. Os direitos fundamentais e a lei: a constituição brasileira tem um sistema de reserva legal?. In: BINENBOJM, Gustavo; SARMENTO, Daniel; SOUZA NETO, Cláudio Pereira de. (Orgs.). Vinte anos da constituição federal de 1988. Rio de Janeiro: Lumem, 2009. p. 605-618.

TORRES, Ricardo Lobo. Curso de Direito financeiro e tributário. 11 ed. Rio de Janeiro: Renovar, 2004.

O mínimo existencial como conteúdo essencial dos direitos fundamentais. In: SOUZA NETO, Cláudio Pereira de Souza; SARMENTO, Daniel. Direitos sociais: fundamentos, judicialização e direitos sociais em espécie. Rio de Janeiro, Lumem, 2008. p. 313-339. 